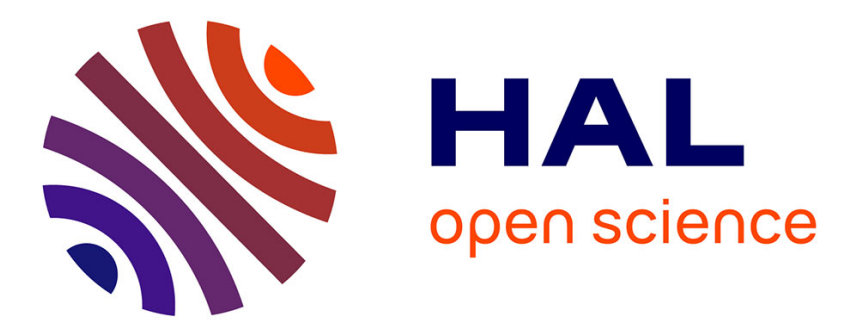

\title{
Comparison of human versus technological support to reduce domestic electricity consumption in France
}

\author{
Morgane Innocent, Agnès François-Lecompte, Nolwenn Roudaut
}

\section{To cite this version:}

Morgane Innocent, Agnès François-Lecompte, Nolwenn Roudaut. Comparison of human versus technological support to reduce domestic electricity consumption in France. Technological Forecasting and Social Change, 2020, 150, pp.119780. 10.1016/j.techfore.2019.119780 . hal-02450849

\section{HAL Id: hal-02450849 \\ https://hal.science/hal-02450849}

Submitted on 21 Dec 2021

HAL is a multi-disciplinary open access archive for the deposit and dissemination of scientific research documents, whether they are published or not. The documents may come from teaching and research institutions in France or abroad, or from public or private research centers.
L'archive ouverte pluridisciplinaire HAL, est destinée au dépôt et à la diffusion de documents scientifiques de niveau recherche, publiés ou non, émanant des établissements d'enseignement et de recherche français ou étrangers, des laboratoires publics ou privés.

\section{다)(1) $(5$}

Distributed under a Creative Commons Attribution - NonCommercial| 4.0 International 


\author{
Morgane Innocent ${ }^{1}$, Postdoctoral researcher in Marketing \\ Université de Bretagne Occidentale, Laboratoire LEGO \\ 20 avenue Victor Le Gorgeu - CS 93837 \\ 29238 Brest cedex 3 \\ France \\ morgane.innocent@univ-brest.fr \\ Agnes Francois-Lecompte, Assistant professor in Marketing \\ Université de Bretagne Sud, Laboratoire LEGO \\ Campus Tohannic-BP 573 \\ 56017 Vannes cedex \\ France \\ agnes.lecompte@univ-ubs.fr \\ Nolwenn Roudaut, Assistant professor in Economics \\ Université de Bretagne Sud, Laboratoire LEGO \\ Campus Tohannic-BP 573 \\ 56017 Vannes cedex \\ France \\ nolwenn.roudaut@univ-ubs.fr
}

This study has received support from the French Environment and Energy Management Agency (ADEME) through the experimental smart-grid SOLENN (SOlidarity-Energy- INnovation) project.

\footnotetext{
${ }^{1}$ corresponding author at all stages of the refereeing process
} 


\section{Comparison of human versus technological support to reduce domestic electricity consumption in France}

In its "Framework for climate and energy", the European Union (EU) addresses a number of issues in relation to climate change. This Framework calls on EU member states to target a $27 \%$ decrease of their energy consumption in 2030 with respect to 1990 levels. This aim is not new and is not specific to Europe (Svenfelt, Engström \& Svane, 2011). Many countries or institutions, such as the Conference of the Parties (COP), are trying to find a way to a more sustainable development including a decrease of primary energy consumption. The role of households is particularly important as they represent the largest consumer group, accounting for $35 \%$ of the total electricity consumption in France (RTE, 2015). Reducing household electricity demand is thus one of the key challenges for public energy policies in Europe and most developed countries.

If the aim is to encourage households to reduce their use of electricity, it is important to examine the effectiveness of the different support systems that can be implemented for this purpose. After having identified the target behaviour (a decrease of electricity consumption by consumers), the next step is to identify and test the external interventions that are most likely to induce the desired change (Geller, 2002, Steg \& Vlek, 2009). In that regard, it appears that many research projects and public programmes for mitigating climate change impact are based on a recourse to digital technologies (Darby, 2010; Hargreaves, Nye \& Burgess, 2010). However, research also shows that it is far from simple to change consumer behaviours (Bull, Lemon, Everitt \& Stuart, 2015). The present article aims to test the impact of various systems for reducing domestic electricity consumption. In particular, we compare the efficiency of two alternative strategies to encourage consumers to engage in more ecologically sustainable behaviour, i.e. using a technological versus a human approach. The first approach is based on technological tools allowing consumers to consult detailed feedback information about their daily electricity consumption (Marikyan, Papagiannidis \& Alamanos, 2019). This approach includes home-automation systems and innovations built upon smart-grids. The second approach relies on providing households with guidance on the topic of electricity, offering them the possibility of interaction as well as learning eco-friendly behaviour from other people's experience. 
The research is based on an experiment conducted between December 2015 and June 2017 including 162 volunteer households in western France. The households were equipped with a smart-meter for monitoring the overall electricity consumption of each participant. The sample was divided into four groups, three of them being subject to different treatments and a control group without any particular treatment. Participants were not randomly assigned to a particular group and were free to choose one treatment or another. This choice could have been influenced by individual characteristics. Consequently, the analysis uses a treatmenteffect methodology (Heckman, Ichimura, Smith \& Todd, 1998) to compare households in terms of their response to the different programmes. In summary, our results suggest that providing detailed information on electricity consumption does not systematically lead to a change of consumers' daily practices. Similarly, without access to detailed information on electricity consumption, a change of consumption behaviour cannot be achieved (Kendel, Lazaric \& Maréchal, 2017). The combined activation of human and technological leverages can trigger an effective decrease of electricity consumption in the short term. This study has important implications for both private and public actors involved in energy transition. It highlights the complementarity of human and technological solutions to induce more ecofriendly types of behaviour in the case of electricity consumption. In particular, we question the efficiency of purely technological approaches for the monitoring of electricity consumption, since consumers need to be assisted through human interaction.

Based on a literature review, the first part of this article presents the hypotheses tested in this research. We then develop the methodological aspects, with a presentation of the experimental design and the statistical procedure used to compare the different experimental treatments. Finally, the last part of the article provides the results and the ensuing conclusions.

\section{Research background and theoretical framework}

\subsection{Research on electricity savings}

Electricity savings (ES) behaviours involve all the choices and actions made by consumers that aim to minimize their home electricity consumption. These behaviours include everyday eco-gestures in various domains (e.g., heating, cooking, lighting and electrical appliances) and the choice of installations and devices (e.g., home appliances, insulation, heating system, use of renewable energy) (Gardner \& Stern, 2002; Abrahamse, 2007; Urban \& Ŝčasnỳ, 2016). 
Behaviours related to ES have been extensively studied in sociology and environmental psychology, in particular to identify their determining factors. These factors are usually classified according to two sets of antecedents: those related to the context or to psychological variables (Wilson \& Dowlatabadi, 2007; Thøgersen \& Gronhoj, 2010).

As far as the contextual determining factors are concerned, studies have shown the influence of the specific features of households as regards domestic appliances, heating and hot waterproducing devices (Sardianou, 2007; Mills \& Schleich, 2012; Ehrhardt-Martinez, Donnelly \& Laitner, 2010; Huebner et al., 2016). Similarly, studies have highlighted the role of sociodemographic factors such as age, gender, income, education level and housing tenure status (Poortinga, Steg, Vlek \& Wiersma, 2003; Gram-Hanssen, Kofod \& Petersen, 2004; Barr, Gilg \& Ford, 2005; Carlsson-Kanayama \& Linden, 2007; Sardianou, 2007; Abrahamse \& Steg, 2009; Ehrhardt-Martinez, Donnelly \& Laitner, 2010; Thøgersen \& Grønhøj, 2010; Stromback, Dromacque \& Yassin, 2011; Chen, Wang \& Steemers, 2013; Jones, Fuertes \& Lomas, 2015).

Concerning the psychological antecedents of ES, two main groups have been identified. The first one relates to variables such as personality traits, values (Schwartz, 1977) and personal norms. These factors are relatively stable for different groups of the population, but do not really account for ES behaviours (Abrahamse, 2007). The second antecedent is related more directly to ES behaviour. It includes ES drivers, deterrents, attitudes (Gadenne, Sharma, Kerr $\&$ Smith, 2011) and ES-related notions of self-efficacy (Lindenberg \& Steg, 2007; Thøgersen $\&$ Grønhøj, 2010), linked to attitudes towards the effectiveness of daily-based actions (Barr \& al., 2005, Botetzagias, Malesios \& Poulou, 2014). Factors such as financial, comfort, and convenience issues and those related to knowledge have positive or negative effects upon people's behaviours (Abrahamse, 2007; Abrahamse \& Steg, 2009; Ek \& Soderholm, 2010; Sweeney, Kresling, Webb, Soutar \& Mazzarol, 2013; Ohler \& Billger, 2014). Another category involves multiple moral issues: preserving the environment, global warming, citizens' responsibility, or even hunting down waste (Stern, 2000; Barr \& al., 2005; Sweeney \& al., 2013).

All these studies deal with the variables involved upstream of behaviours, but are insufficient to identify efficient programmes leading to behavioural change. The present study focuses on this specific topic and aims to analyse the effectiveness of different strategies to induce more efficient ES behaviours. In a general manner, strategies to induce pro-environmental behaviours either act on the information given to consumers or on the costs/benefits of the behaviour (Steg \& Vlek, 2009). 
In the field of electricity consumption, much research has concentrated on the first type of intervention, and more precisely the impact of providing more feedback to consumers (Darby, 2010; Hargreaves \& al., 2010). This feedback consists of giving people information about their electricity consumption, and has proven to be an effective way to promote proenvironment behaviours (Abrahamse \& Matthies, 2018). The central assumption is that providing feedback on energy consumption makes electricity visible, thus raising awareness and thereby encouraging individuals to make a rational decision to reduce their consumption (Hargreaves \& al., 2010). Feedback could also overcome several barriers to behavioral change such as perceived self-efficacy, knowledge of eco-gesture efficiency, or a rebound effect after the purchase of an energy-efficient appliance (Gifford, 2011). Based on 36 studies carried out between 1995 and 2010, Ehrhardt-Martinez, Donnelly \& Laitner (2010) give an overview of the average household electricity savings by feedback type. They draw a distinction between "indirect feedback", provided, for example, by an enhanced billing statement or a weekly estimated consumption, and "direct feedback", which provides real-time information, ideally down to the appliance level. Electricity-savings can vary from $4 \%$ to $12 \%$ depending to the type of feedback. The "direct feedback" solution involves the implementation of technical solutions, such as electronic devices. In fact, these solutions provide a tool for customers to better control their consumption and ultimately save energy (Fischer, 2008). It has been shown to be effective in changing heating behaviours (Jensen, Holtz \& Chappin, 2015). Based on a meta-analysis, Ehrhardt-Martinez \& al. (2010) conclude more generally that "Providing households with frequent, ongoing, and meaningful feedback regarding their energy consumption practices results in significant residential sector energy savings while engaging people to become part of the energy solution” (Ehrhardt-Martinez \& al., 2010).

Another option to encourage households to reduce their energy use on a voluntary basis is to adopt a more tailored and human approach (Abrahamse, 2007). Under that option, households are encouraged to change their behavior by means of interactions with experts on electricity savings aspects. This could take the form of collective workshops in which information about energy-saving measures is given through advice. These workshops address the "why" and "how" questions of participants about ES behaviors. Consequently, the aim of such workshops is to lead to higher levels of concern about climate change, to increased knowledge about energy conservation, and finally to enhance ES behaviors. These types of support are not only based on a "top down" communication of skills and knowledge but also use a lateral communication process based on human relationships, citizen friendliness and the sharing of experiences and ideas between participants (Sweeney \& al., 2014). The "Carbone 
Conversations" is a good example of this type of initiative even if these meetings address climate change in all its daily aspects (Buchs, Hinten \& Smith, 2015). In a closely related idea, the coaching can be personalized. In such an approach, an expert comes into the home and can adapt his or her advice to each individual case. This solution is time consuming but an advantage of this approach is that participants receive relevant information only, rather than general information which may not always apply to a given household situation (Abrahamse, Steg, Vlek \& Rothengatter, 2005). In France, several recent programmes have been based on home audits, such as the Trak O'Watts initiative (www.trakowatts.bzh). Several studies have analysed the effectiveness of human approaches which mix awareness to climate change with teaching on how to act as an individual (see Abrahamse, 2007 for a synthesis).

\subsection{Hypotheses}

Overall, except in the case of economic leverage, solutions for enhancing ES behaviors can be divided into two competing approaches, one based on a technological pillar allowing a detailed and real-time feedback on electricity consumption to consumers, and another based on a human pillar where consumers can interact with experts and benefit from a tailored support. The existing research literature offers a view on the way each solution operates on consumers. However, these studies suffer from two main limitations: firstly, they do not always measure the evolution of behaviors in time or under real conditions of use for consumers; secondly, they focus on a single solution that prevents a true comparison of the effectiveness of support systems.

Based on the above findings, the purpose of this study is to test and compare the effects of technological versus human support systems on consumer behaviour. The first support system is based on the transmission of information to consumers on their electricity consumption, whereas the second system is based on learning, awareness and know-how of eco-friendly gestures.

Based on the existing body of literature, it is hypothesized that:

H1: Households who receive technological support providing detailed feedback on their electricity consumption show a greater reduction in their electricity consumption compared to individuals without any support system. 
$\mathrm{H} 2$ : Households who receive human support by coaching show a greater reduction in their electricity consumption compared to individuals without any support system.

Furthermore, following Abrahamse (2007), we posit that interventions work better when used in combination. Since these interventions operate on distinct drivers, it is then assumed that they act more efficiently compared to a single solution.

H3: Households who receive both human and technological support systems show a greater reduction in their electricity consumption compared to individuals receiving a single support system.

\section{Methodological aspects}

\subsection{Presentation of the experiment}

The study was conducted during the years 2015 and 2017 as part of an experimental electric Smart Grid in the Brittany Region. Electric smart grids are "smart" networks that rely on new technologies to promote better communication between consumers and electricity producers and better management of the electricity network. In France, their development is based on the "Linky" smart meters.

The project aimed to test, under real conditions, the impact of several support systems on electricity consumption on a sample of households. More precisely, the sample was divided into four distinct groups, each one corresponding to a particular experimental condition. The experimental design was based on the voluntary participation of individuals, even if the households had been recruited by means of a canvassing method. The participation of these individuals included answering several surveys ${ }^{1}$ throughout the duration of the project. All participants were also equipped with a "Linky" smart-meter for monitoring the overall electricity consumption in each household.

\subsubsection{Experiment design}

As mentioned, the sample is divided into four groups, three of them being subject to different treatments and a control group without any particular treatment.

\footnotetext{
${ }^{1}$ Surveys were conducted by a market research company using both on-line and phoning methods to maximize participants' response rate.
} 
The first group, called Home Automation System (HAS) $(n=18)$, was equipped with a home automation system for monitoring electricity consumption at a disaggregated level (heating, lighting, hot water, etc.). This was implemented by means of a home-based device and personal access to a dedicated web site. This group corresponds to a "purely technological" type of solution that allows consumers to measure their own electricity consumption in detail.

The second group, called Collective Coaching (CC) $(n=27)$, was invited to participate in periodic collective workshops organized by the local energy agency which were focused on eco-friendly gestures with respect to electricity consumption. The purpose of these meetings was to create awareness among participants and to teach them how to reduce electricity consumption through daily gestures. This second group corresponds to a "purely human" type of approach, with no action to make detailed home energy monitoring available for consumers.

The third group, Individual Coaching (IC) $(n=28)$ was offered personal coaching by the local energy agency; this included six home visits, measurement of the electricity consumption of appliances and personalized advice to reduce energy consumption. In that case, people could benefit from both a home-based device and personalized interaction with an expert. Then this third group represents the case of a "mixed approach" based on both human and technological support.

Finally, one group ( $n=89)$ without any treatment was integrated into the study to assess the possible effects of participation in the experiment on electricity consumption. The simple fact of being monitored for overall electricity consumption (by means of smart-meter) may induce a behavioural change, and may lead to a decrease in electricity consumption. This group received no incitation to save electricity and represents the Control Group (CG).

As summarized in Fig. 1, the four conditions can be divided into two electricity reduction support systems: a human approach versus a technological approach.

To test our hypotheses, five comparisons are made with the control group. Three of the comparisons involve tests between each treated group and the control group. The two other tests deal with composite groups, one corresponding to the human approach (Collective coaching + Individual coaching) and the other to the technological approach (Individual coaching + Home automation system). 
Figure 1. Synthesis of the experiment design

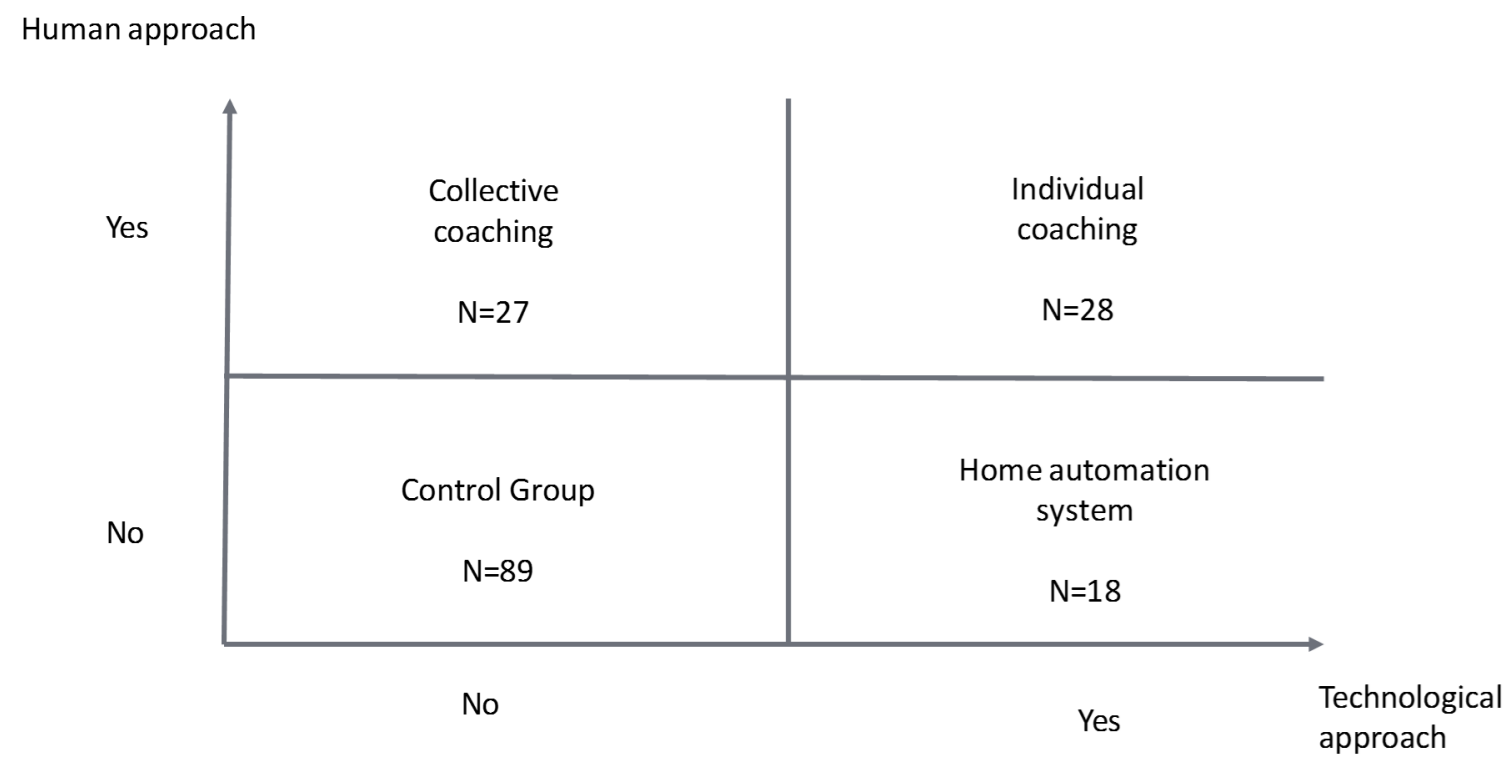

\subsubsection{Sample presentation}

A total of 675 individuals were recruited at the start of the experiment. Numerous participating households left the project during the first year and various difficulties arose in collecting accurate data on electricity consumption (missing data, defective smart-meter data transmission, etc.). Finally, the data corresponding to a sample of 162 respondents are available for a comparison of behaviours over time. The characteristics of the sample are presented in Table 1.

During the recruitment step, future participants were invited to choose between the four proposed treatments. As the data show, the distributions are not the same for the four groups. For example, the HAS group is characterised by an over-representation of male participants, with around $80 \%$ of the sample younger than 65 , made up of owners having a family of three persons or more. The IC group is older, with a majority of two-person families. 
Table 1. Descriptive statistics of the sample and the four groups

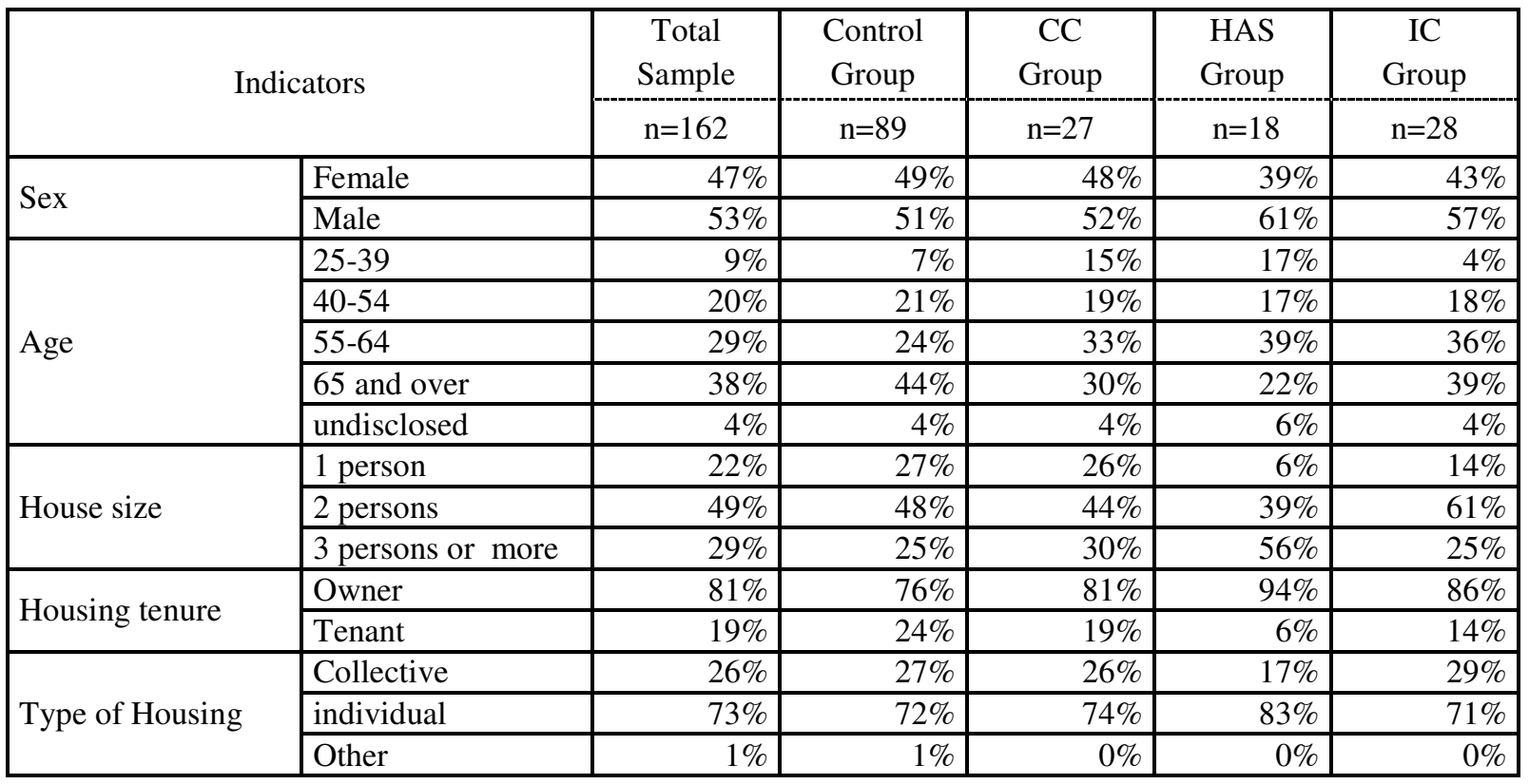

\subsubsection{Outcome variables}

Two outcome variables are used to evaluate the impact of the different treatments.

The evolution of electricity consumption over time. Firstly, the electricity consumption of the households in the four groups was measured by smart-meters. Consumption is compared over two six-month periods: from January to June $2016\left(\mathrm{P}_{1}\right)$, during which the different types of approach were progressively applied and a second period $\left(\mathrm{P}_{2}\right)$, from January to June 2017, during which the treatments were continued. The total consumption for each period is measured in kilowatt-hours $(\mathrm{kWh})$ and is called the "Electricity Index" (EI). To compensate for the effect of the consumption level of the households, the Evolution of the Electricity Index (EV EI) between the two periods $\mathrm{P}_{1}$ and $\mathrm{P}_{2}$ is calculated for each household:

$$
E V E I=\frac{E I_{P 2}-E I_{P 1}}{E I_{P 1}}
$$

Evolution in the practice of eco-friendly gestures. In addition to this measurement, a survey was conducted on participants at the end of the first period (called T1) and at the end of the second period (called T2). These surveys included a measurement of the level of electricity eco-friendly gestures declared by the respondent. The measure of the intensity of Electricity savings Practice (EPI) used here is derived from the index developed by Thøgersen and 
Grønhøj (2010), but is adapted to the French context. The original index comprised 17 items detailing simple and more technical eco-friendly gestures helping to reduce electricity consumption at home. After cleaning the data and adaptation to the French context, the final measure includes 13 items, which are listed in Fig. 2. Some items were deleted due to the low prevalence of equipment (tumble dryer, dishwasher) or certain cultural differences (like the use of vacuum flasks for coffee). Thus, the 13 items are a set of actions that can be performed in a French household to save electricity, regardless of the characteristics of the housing (size, mode of heating, etc.). The structure of the measure is similar to a Rasch model (Thøgersen \& Grønhøj, 2010; Urban \& Ščasný, 2016), in which the most common eco-friendly gestures are also the simplest. An individual with a basic eco-friendly practice will simply turn off the lights and television, while an individual with a more advanced practice will make use of low consumption bulbs and will be careful to not leave devices on standby mode. The similarity of the EPI index to a Rasch scale is reflected in a separation reliability coefficient of .67 very close to the standard of .70 (Petrillo, Cano, McLeod \& Coon, 2015). In line with Thøgersen and Grønhøj (2010), we operate this variable using the mean score of the responses to the 13 items on a 5-point scale. In addition, to assess the nomological validity of the measure, we use a regression to test the influence of a known determinant of EPI the Intended purpose to save electricity (Thøgersen \& Grønhøj, 2010), on EPI (in T1). The results show that the Intended purpose to save electricity explains $19.3 \%(\mathrm{~F}=38.279)$ of the index EPI, with an estimated parameter value of $0.44(\mathrm{t}=6.187)$.

Once the EPI scores for $T_{1}$ and $T_{2}$ are calculated, the evolution of Electricity savings Practice Intensity (EPI) between the two periods is determined for each household:

$$
E V E P I=\frac{E P I_{T 2}-E P I_{T 1}}{E P I_{T 1}}
$$


Figure 2. Measure of the intensity of electricity saving practice (EPI)

\section{How often do you ... (Never/ Rarely/ Half the time/ Often / Always)}

1_Switch off the light when you are the last person to leave a room?

2_Purchase energy-saving light bulbs such as compact fluorescent light bulbs (CFLs) or LED bulbs?

3_Start the washing machine when it is not full? (reversed item)

4_Swith the TV off when nobody's watching it?

5_Swith the computer off when nobody's using it?

6_ Switch off appliances in stand-by mode?

7_Thaw frozen foods in the refrigerator?

8_Put a lid on the pan when you are boiling food (e.g., pasta, vegetables, eggs)?

9_Switch the oven off a few minutes before the end of cooking time in order to take advantage of oven inertia?

How often do you ... (Never/ Rarely/ Regularly/ Often/ Very often)

10_Control the temperature inside your refrigerator?

11_Control the temperature inside your freezer?

Do you pay attention to ... (Not at all/ A little/ Moderately/ A lot/ Extremely)

12_The renewability of the electricity you use at home?

13_The information regarding the electricity consumption of the appliances you purchase, such as the information provided on the energy labels?

\subsection{The treatment-effect measurement}

The analysis uses a treatment-effect methodology (Heckman \& al., 1998) allowing us to compare the four groups in terms of their response to the different treatments by controlling and neutralizing the impact of effects other than those due to the treatments.

As households are self-selected into the four groups, there is no guarantee that the behavioural change depends solely on the treatment (Hartman, 1988). In our case, this means that comparing average variations of electric consumption or EPI between groups is inappropriate. In fact, there are probably some individual characteristics that can affect the choice of a particular treatment as well as electricity consumption or electricity savings practice. For example, larger households, or those with children, could be more willing to reduce their electricity consumption (Mills \& Schleich, 2012) and thus participate in programmes. In that case, electricity consumption is reduced not only because these households are treated but also because they are more likely to change their habits.

The advantage of a treatment-effect methodology is that it can identify and neutralize the contextual and psychological factors (called covariates), such as household characteristics, equipment or individual attitudinal factors that could impact the results, considered apart from 
the treatment. In other words, treatment participation has to be independent of the outcome variables conditionally on chosen covariates (Lechner, 2001).

For this study, we choose the procedure known as Propensity Score Matching (Caliendo \& Kopeinig, 2008) referred to here as PSM. In a general manner, this method can be presented in two steps: firstly, estimation of the probability to be treated and, secondly, based on this probability, evaluation of the effect of a specific treatment on outcomes. This procedure is performed by calculating an indicator called the Average Treatment Effect (ATE). For example, if, on average, treated individuals reduce their Electricity Index more that they would if they were not treated, then ATE will be significantly negative (and vice versa for the non-treated individuals). In this case, the conclusion is that the treatment helps to significantly reduce the Electricity Index. Then, the expected sign is negative for ATE related to the Electricity index and positive for ATE related to Practice intensity (the treatment helps to significantly enhance the Practice Intensity).

\subsubsection{Estimating the probability of treatment}

Firstly, the probability of a household to be treated is estimated, by calculating the propensity score. The aim is to create a "matching model" for each group of the experiment, and then select proper covariates for each group.

This selection has to comply with a number of rules (Caliendo \& Kopeinig, 2008). Firstly, the potential covariates are selected from previous studies on the subject. That explains why the potential covariates have been selected from the contextual and psychological key factors set out in the first section. Secondly, the covariates have to be independent from the participation and from the anticipation of the treatment. For example, the psychological factors of the participants have to be measured before the start of the experiment.

The propensity score must explain, but not entirely, the participation of the households: if a group is entirely concentrated on one specific modality of a covariate, this covariate must be excluded from the matching model. In other words, individuals/households with the same characteristics must be present in treated and non-treated groups.

In our study, we faced an additional constraint due to the small number of observations. Thus, we use a parsimony criterion which means that only the significant covariates are included in the models (Heckman \& al., 1998; Bryson, Dorsett \& Purdon, 2002). The list of covariates available for the study is presented in Annex 1. 
Since we are estimating the probability of a household to be treated, logit or probit models (for an example see Caragliu and Del Bo, 2018) are preferable options compared to linear probability models (Caliendo \& Kopeinig, 2008). We chose a logit specification that is applied to the five treatment conditions.

\subsubsection{Evaluating the effect of the treatment}

Once the probability to be treated has been estimated, the PSM procedure uses this probability to match households and then goes on to estimate counterfactual outcomes.

The general idea is to compare "matching" outcomes of treated and non-treated households. In other words, for a particular treated household, we compare its actual consumption with the one that the household would have had if it has not been treated. This fictitious consumption, called a counterfactual outcome, can be estimated using the consumption of households in the sample with almost the same characteristics. This corresponds to the matching step.

Different matching algorithms are available. They broadly differ regarding the definition of neighbourhood and the weights assigned to neighbours. In this study, we use the most straightforward matching estimator, i.e. nearest neighbour (NN) matching. The individual from the comparison group is chosen as a matching partner for a treated individual that is closest in terms of the propensity score (Caliendo \& Kopeinig, 2008).

Once satisfactory estimation models are drawn up, the treatment effect is evaluated in terms of the Average Treatment Effect (ATE), which is the mean of the difference between outcome variables (counterfactual and observed) of all households (treated and non-treated).

\section{Results}

This section is organized in two parts. Firstly, we present a set of descriptive statistics and secondly, an analysis of the results of the treatment-effect methodology.

\subsection{Descriptive statistics}

Table 2 summarizes the means of the outcome variables, EV EI and EV EPI, for the different treatment groups (the means and standard deviations of the variables used to define the outcomes variables are reported in annex 2). As expected, the statistics show that the experiment produces a decrease in the electricity consumption of the participants $(-4.17 \%)$, but only a small increase in their declared electricity savings $(+0.98 \%)$. When we look at a disaggregated level, it appears that the four groups of participants lowered their electricity 
consumption, by $2 \%$ for the control group and $7.5 \%$ for the individual coaching group (Fig. 3). Regarding the declared eco-friendly gestures, the collective coaching group and the control group remain at a similar level for the two periods (Fig. 4). The individual coaching group again shows the highest increase, followed by the home-automation solution group.

Overall, the human support system approach is characterized by a decrease of $6.5 \%$ in electricity consumption and an increase of $3.2 \%$ in the declared electricity savings. For the technological support system, the mean values of EV EI and EV EPI are $-7.4 \%$ and $4.5 \%$ respectively.

Interestingly, these results reveal an effect of being part of the experiment, since the control group changed its behaviour. More precisely, the 89 households without treatment consumed $2 \%$ less electricity in the second period comparing to the first period. This shows the need to analyse the results in more detail though a methodology isolating the treatment effect.

Table 2.Means of the outcome variables of the experiment

\begin{tabular}{|l|c|c|c|}
\cline { 2 - 4 } \multicolumn{1}{c|}{} & $\mathrm{N}$ & $\begin{array}{c}\text { EV EI } \\
\text { Mean }\end{array}$ & $\begin{array}{c}\text { EV EPI } \\
\text { Mean }\end{array}$ \\
\hline Total & 162 & $-4.2 \%$ & $1 \%$ \\
\hline Control Group (CG) & 89 & $-2.1 \%$ & $-0.6 \%$ \\
\hline Collective coaching (CC) & 27 & $-5.5 \%$ & $0.3 \%$ \\
\hline Home Automation system (HAS) & 18 & $-7.4 \%$ & $2.1 \%$ \\
\hline Individual Coaching (IC) & 28 & $-7.5 \%$ & $6.1 \%$ \\
\hline Human Support (CC+IC) & 55 & $-6.5 \%$ & $3.2 \%$ \\
\hline Technological support (HAS+IC) & 46 & $-7.4 \%$ & $4.5 \%$ \\
\hline
\end{tabular}

Figure 3. Evolution of electricity consumption EI (in K-Watt-hour) between the two periods for the four groups

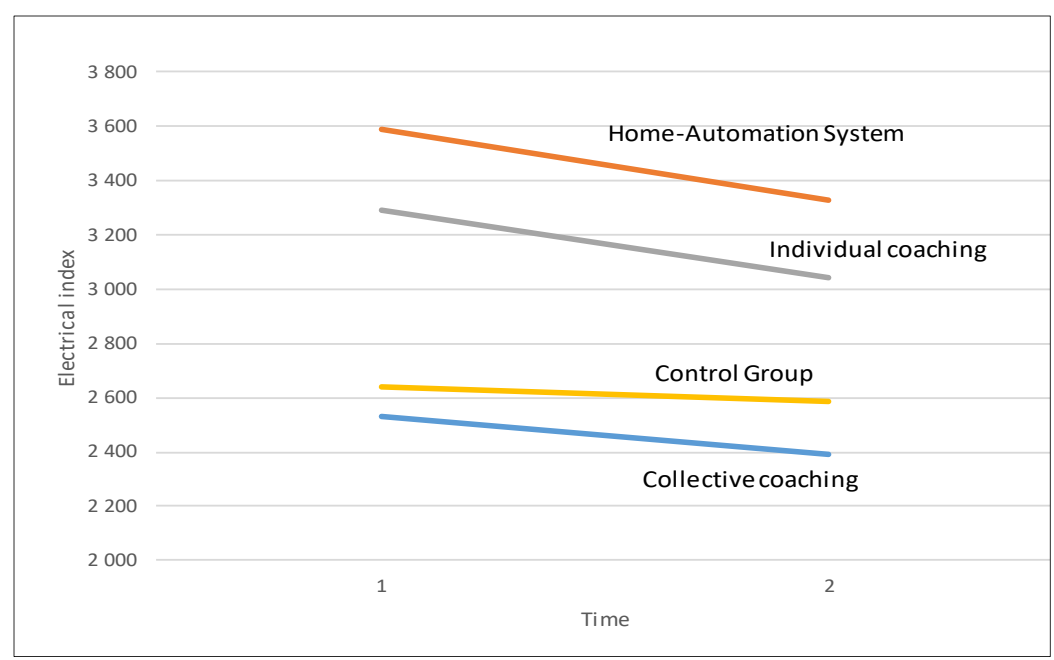


Figure 4. Evolution of the declared electricity-savings practice, EPI, between the two periods for the four groups

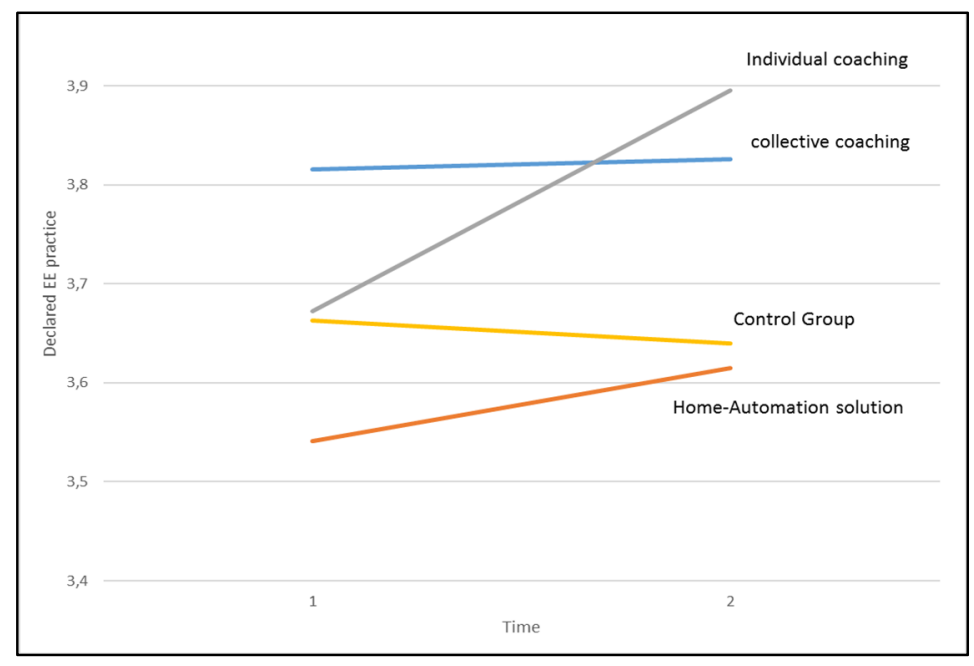

\subsection{Results of the treatment-effect measurement}

The treatment-effect methodology was applied to both the electricity index and the declared electricity savings. Five comparison tests were performed for both indicators as shown in Table 3.

\subsubsection{Estimating the probability to choose a treatment}

Five logit models are estimated. This first step of the PSM procedure leads to the selection of covariates that explain in the best possible way the choice of a specific group by an individual. Originally, 16 covariates taken from the literature were included in the models (see Annex 1). Nine of these covariates prove to have an impact on the choice of treatment by the households, some of them after categorical transformation, and two of them show an additional quadratic effect. Ultimately, twelve covariates are used in the five models. The results are presented in Table 3 , which reports the regression parameter and its significance $(\mathrm{t}$ test and $\mathrm{P}$ value) for each covariate.

These results show that different factors like individual characteristics (Energy culture, attitude towards the effectiveness of daily gestures, or the intended purpose to save energy), or households characteristics (such as house size and the status of occupiers) and dwelling characteristics (surface area, date of construction, heating system and the number of electric appliances) can be identified as determinants of the willingness to participate or not in programmes. For example, members of IC and HAS groups (and consequently IC+CC and IC+HAS groups as well) show a lower perception of daily gestures effectiveness compared to 
the control group (regression parameters are significant and positive). This differs from the $\mathrm{CC}$ group for which this is not a significant covariate.

For the two continuous variables (Surface area of the housing and number of electric appliances), quadratic effects are observed.

While the choice of individual coaching and Home-automation support system are accurately explained by the models, the choice of Collective coaching appears to be more difficult to explain.

The aim of this first step of the PSM procedure is to predict the probability to be treated for each household. Then, at the matching step for a given treated household, we are looking for similar households that are not treated (similarity is based on the propensity scores calculated in the first step). These households give information about the level of outcome this particular household would have if it was not treated (counterfactual outcome). The ATE measure is obtained by performing this step for each household in the sample and calculating the average of the differences between observed and counterfactual outcomes.

Table 3.Results of the Logit regressions: determinants of participation in the experiment

\begin{tabular}{|c|c|c|c|c|c|}
\hline & $\begin{array}{l}\text { (1) } \\
\text { IC }\end{array}$ & $\begin{array}{l}\text { (2) } \\
\text { HAS }\end{array}$ & $\begin{array}{l}\text { (3) } \\
\text { CC }\end{array}$ & $\begin{array}{c}(4) \\
\mathrm{IC}+\mathrm{CC}\end{array}$ & $\begin{array}{c}(5) \\
\text { IC+HAS }\end{array}$ \\
\hline Surface area & \multirow{12}{*}{$\begin{array}{c}-0.02 \\
(-1.33) \\
1.12 \times 10^{-4 *} \\
(1.79) \\
-0.51^{*} \\
(-1.71) \\
-0.82^{*} \\
(-1.86) \\
0.70^{* *} \\
(2.36)\end{array}$} & \multirow{12}{*}{$\begin{array}{c}0.66^{* *} \\
(2.00) \\
0.54 \\
(0.97) \\
1.11^{*} \\
(1.94) \\
1.34^{* *} \\
(1.99) \\
0.76^{*} \\
(1.82)\end{array}$} & \multirow{9}{*}{$\begin{array}{c}-0.03 \\
(-1.32) \\
1.19 \times 10^{-4} \\
(1.41)\end{array}$} & \multirow{3}{*}{\begin{tabular}{|c|}
$-0.03^{*}$ \\
$(-1.75)$ \\
$1.19 \times 10^{-4^{* *}}$ \\
$(2.01)$ \\
-0.16 \\
$(-0.65)$
\end{tabular}} & \multirow{3}{*}{$\begin{array}{c}-0.05^{* *} \\
(-2.45) \\
1.9 \times 10^{-4 * * *} \\
(2.58) \\
-0.27 \\
(-0.98)\end{array}$} \\
\hline$(\text { Surface area })^{2}$ & & & & & \\
\hline Electric Heating & & & & & \\
\hline $\begin{array}{l}\text { Strong Intended purpose to save } \\
\text { electricity }\end{array}$ & & & & $\begin{array}{l}-0.17 \\
(-.62)\end{array}$ & $\begin{array}{l}-0.70^{*} \\
(-1.87)\end{array}$ \\
\hline $\begin{array}{l}\text { Low perception of daily gestures } \\
\text { effectiveness }\end{array}$ & & & & $\begin{array}{l}0.42^{*} \\
(1.73)\end{array}$ & $\begin{array}{l}0.73^{* * * *} \\
(2.78)\end{array}$ \\
\hline 2-person household & & & & & $\begin{array}{l}0.81^{*} \\
(1.93)\end{array}$ \\
\hline 3-person household & & & & & $\begin{array}{l}1.09^{* *} \\
(2.33)\end{array}$ \\
\hline Owners & & & & & $\begin{array}{l}1.13^{* *} \\
(2.53)\end{array}$ \\
\hline $\begin{array}{l}\text { Newer dwelling } \\
\text { (built after 2004) }\end{array}$ & & & & & $\begin{array}{c}0.43 \\
(1.27)\end{array}$ \\
\hline Strong Energy culture & & & \multirow{3}{*}{$\begin{array}{c}0.47 \\
(1.47) \\
0.48^{*} \\
(1.72) \\
-0.01^{*} \\
(-1.67)\end{array}$} & $\begin{array}{c}0.37 \\
(1.32)\end{array}$ & \\
\hline Number of electric appliances & & & & $\begin{array}{l}0.25 \\
(1.33)\end{array}$ & \\
\hline (Number of electric appliances) $)^{2}$ & & & & $\begin{array}{l}-0.01 \\
(-1.18)\end{array}$ & \\
\hline Constant term & $\begin{array}{c}0.81 \\
(0.75) \\
\end{array}$ & $\begin{array}{l}-3.32^{* * * *} \\
(-3.86)\end{array}$ & $\begin{array}{l}-3.76 \\
(-1.54)\end{array}$ & $\begin{array}{l}-1.33 \\
(-0.82)\end{array}$ & $\begin{array}{c}0.83 \\
(0.77) \\
\end{array}$ \\
\hline $\begin{array}{l}N \\
\text { Pseudo } R^{2}\end{array}$ & $\begin{array}{l}116 \\
\mathbf{0 . 1 5}\end{array}$ & $\begin{array}{l}107 \\
\mathbf{0 . 2 0}\end{array}$ & $\begin{array}{l}115 \\
\mathbf{0 . 0 5}\end{array}$ & $\begin{array}{l}143 \\
\mathbf{0 . 0 6}\end{array}$ & $\begin{array}{l}134 \\
\mathbf{0 . 1 9}\end{array}$ \\
\hline
\end{tabular}

Estimated parameters; $t$ statistics in parentheses; ${ }^{*} p<0.10,{ }^{* * *} p<0.05,{ }^{* * *} p<0.01$ 


\subsubsection{Outcome of the PSM procedure: Average treatment effect}

We estimate the impact of technological and human supports on electricity savings (EV EI), and Eco-friendly gestures practice intensity (EV EPI) by looking at the average treatment effects (respectively ATE1 and ATE2) for the different type of supports, i.e. Individual coaching, Home-automation system, Collective coaching, and more broadly with the subpanel involving both technological and human support. Results are reported in Table 4.

First, the significance level of ATE provides information about the effectiveness of the treatment. If ATE is not significantly different from zero, then this means that there are no significant differences between observed and counterfactual outcomes: being treated or not has the same impact on variations of the electricity index or variations of the practice intensity. For example, the Electricity index shows a decrease between P1 and P2 for each group (see Fig. 3), but this decrease is no greater for some treatment groups (Homeautomation system (ATE1=-.09) and Collective Coaching (ATE1=.03) compared with the control group.

Secondly, for the significant ATE, we find that ATE1 is negative and ATE2 is positive, which is as expected.

Table 4. Results of the treatment-effect methodology

\begin{tabular}{|c|c|c|c|c|c|c|}
\hline & \multicolumn{2}{|c|}{$\begin{array}{l}\text { Electricity Index } \\
\text { EV EI }\end{array}$} & \multicolumn{2}{|c|}{$\begin{array}{c}\text { Practice intensity } \\
\text { EV EPI }\end{array}$} & \multirow{2}{*}{$\begin{array}{l}\text { Type of } \\
\text { support }\end{array}$} & \multirow{2}{*}{ Effect } \\
\hline & ATE1 & t-stat & ATE2 & t-stat & & \\
\hline $\begin{array}{l}\text { Individual coaching (IC) } \\
\text { versus CG }\end{array}$ & $-.09^{* * *}$ & $(-6.94)$ & $.25^{* * *}$ & $(3.66)$ & $\begin{array}{l}\text { Human }+ \\
\text { technological }\end{array}$ & Yes \\
\hline $\begin{array}{l}\text { Home-automation system (HAS) } \\
\text { versus CG }\end{array}$ & -.09 & ns & -.21 & ns & Technological & No \\
\hline $\begin{array}{l}\text { Collective coaching }(\mathrm{CC}) \\
\text { versus } \mathrm{CG}\end{array}$ & -.03 & ns & $.20^{* *}$ & $(2.04)$ & Human & Yes \\
\hline $\begin{array}{l}\text { Human support systems }(\mathrm{CC}+\mathrm{IC}) \\
\text { versus CG }\end{array}$ & $-.06^{* *}$ & $(-2.52)$ & $.20^{* * * *}$ & $(2.64)$ & Human & Yes \\
\hline $\begin{array}{l}\text { Technological support (HAS + IC) } \\
\text { versus CG }\end{array}$ & $-.11^{* * *}$ & $(-4.23)$ & .12 & ns & Technological & No \\
\hline
\end{tabular}

More precisely, a significant decrease in electricity consumption (EI) and a significant increase of daily eco-friendly gestures (EPI) is only observed in the "mixed approach" group, i.e. the Individual coaching group (IC). The Collective coaching group (CC) increased its practice of daily eco-friendly gestures, but this did not give rise to significant electricity savings. There is no significant effect regarding the Home-automation system group (HAS). 
Indeed, ATE1 estimation reflecting the rate of variation of the electricity index is not significant. Simultaneously, estimation of daily eco-friendly gestures based on ATE2 reveals no significant evolution of the effective behaviour. The results regarding HAS are discussed further below in the limitations section.

Finally, cross-group comparison tests show that technological support (HAS + IC) effectively helps households to decrease their electricity consumption, without effects on daily ecofriendly behaviour, while the Human support system $(\mathrm{CC}+\mathrm{IC})$ has a significant effect on daily behaviour and a moderate effect on electricity consumption.

\section{Discussion and conclusions}

It should be borne in mind that hypotheses H1 and H2 assume that technological (H1)/ human (H2) support leads to a reduction of the electricity consumption of the household. As table 4 shows, both the technological approach providing a detailed feedback (H1, validated by ATE1 $(H A S+I C)$ significance), and the human approach by means of coaching (H2, validated by ATE1 $(C C+I C)$ significance $)$ help Households to reduce their electricity consumption. Hypotheses $\mathrm{H} 1$ and $\mathrm{H} 2$ are thus validated.

Furthermore, the third hypothesis can also be confirmed since households having received both support systems (IC group) show a greater reduction in electricity consumption compared to those receiving a single support system (H3, validated by ATE1 (IC) value of $0.09 * * *)$.

Nevertheless, our findings regarding $\mathrm{H} 1$ and $\mathrm{H} 2$ are more subtle than expected. It appears that the effect of human or technological support is significant only at the aggregate level, that is when bringing together IC and CG for the human approach, and IC and HAS for the technological approach. Two treatments, HAS and CG, show either mixed or no results when taken in isolation. A detailed analysis of the effects of the three treatments shows variations in the manner of operation of the different supports.

The human approach is shown to be effective on both outcome variables at the aggregate level. This implies, for example, the effectiveness of know-how transmission by demonstration. However, in the case of collective coaching (CC), there is an impact on frequency of daily eco-friendly gestures but not on electricity consumption. As the coaching 
only concerns individuals involved in the experiment, this approach does not necessarily lead to a decrease in the electricity consumption at the level of the household (ATE1 (CC) not significant). The participant might have some difficulties in triggering positive changes at the family scale. Additionally, without detailed information on his/her own consumption, it could be difficult to identify the most effective actions for electricity-savings.

Regarding the technological support, individual coaching leads to a decrease of the electricity consumption and an increase in daily eco-friendly gestures (AT1 and ATE2 (IC) are significant). But the Home-automation support alone does not induce an increase of daily ecofriendly gestures. Then, we can suppose that the drop in consumption would result from other factors, such as home insulation, or the buying of more efficient electrical appliances (Gardner \& Stern, 2002; Abrahamse, 2007; Urban \& Ŝ̌̌asnỳ, 2016).

These results suggest that providing detailed information of electricity consumption does not systematically lead to a change of consumers' daily practices. Similarly, without access to detailed information on electricity consumption, a change of consumer behaviour leading to energy savings cannot occur (Kendel \& al., 2017). In summary, only a combined activation of human and technological leverages can trigger a major change of electricity consumption in the short term.

\section{Implications and recommendations}

This study has important implications for both private and public actors involved in the energy transition. It highlights the complementarity of human and technological solutions to induce more eco-friendly types of behaviour as regards electricity consumption. In particular, we question the efficiency of purely technological approaches for the monitoring of electricity consumption, since consumers need to be assisted through human interaction.

As illustrated in this research, electric smart-grid solutions offer suitable tools for the monitoring household electricity consumption. As such, smart-grids are considered as key enablers for the implementation of the smart city paradigm (Betis, Cassandras \& Nucci, 2018). This concept has rapidly risen to prominence within industry, especially in the context of policy programmes against climate change, and is well on its way to becoming the leading driver of urban sustainability (de Jong, Joss, Schraven, Zhan \& Weijnen, 2015). 
Based on such perspectives and expectations, Martin, Evans and Karvonen (2018) stress that digital technologies are envisaged as "solutions" to urban sustainability problems. These latter authors highlight several tensions between the smart city and the goals of sustainable development; some of these tensions are directly connected with the results of our study. These authors also note that digital innovations have been designed based on the assumption that structural problems can be resolved through changes in the behaviour of individual citizens. This assumes a rational choice model that connects information provision with residential behaviour (Karvonen, 2013; McMeekin \& Southerton, 2012). Smart-grids, in Smart cities, for example, will be able to empower citizens to make better decisions based upon the data created by smart infrastructure (Caragliu \& Del Bo, 2012; Viitanen \& Kingston, 2014). Our results show that, in the absence of Human support, the process of transformation from information into new behaviours does not systematically occur.

Our results outline a possible new vision on smart-grids and smart-cities, based not only on technology but also on its synergy with programmes fostering human relationships, citizen friendliness and the sharing of experiences and ideas. Taking this synergy into account could provide a new roadmap for local policies aiming to use digital technologies to empower citizens (Martin \& al., 2018). At present, the main issue seems to place citizens/consumers at the heart of the action, and to make sure that they appropriate technological tools in their daily practices (Innocent \& Francois-Lecompte, 2018).

This clearly raises the problem of the cost of such ambitions. In the context of the experiment, a cost-benefit analysis of the different types of support shows that individual coaching is four times more expensive than collective coaching (Lallouet, 2018). In the case of home automation support, the initial installation represented about half of the cost of individual coaching. Solutions to induce electricity savings at a large scale should then take into account the cost and feasibility of their implementation.

In a nutshell, this study leads to the conclusion that a balanced distribution of resources is necessary to accelerate the energy transition, which should be directed both towards the diffusion of new technologies and the appropriation of these tools by citizens through human support. 


\section{Limitations and future research}

The main limitations of this study are the relatively small size of the sample and the short duration of the experiment - i.e. the comparison of results was obtained over only two time periods. The small size of the sub-panels, more specifically concerning the Home-automation support system, might reduce the validity of the results. Surprisingly, the $9 \%$ decrease of electricity consumption for the Home-automation support group is not statistically significant, which gives an illustration of this limitation. In addition, the short duration of the experiment prevents us from taking a potential rebound effect into account (Sorrell, Dimitropoulos \& Sommerville, 2009). Nevertheless, it should be borne in mind that the experiment was conducted under real conditions, and that households were involved in the study over a long period of time.

A second limitation is that our methodology does not allow us to identify whether the efficiency of the different support systems is impacted by some socio-economic variables (socio-professional category, age, housing tenure etc.). This would involve measuring the influence of these variables, all other things being equal, within each studied group. Such tests would also require larger samples to isolate the impact of different socioeconomic variables. This could be an interesting extension of the present research, in order to define a more precise target for a particular approach.

In conclusion, it appears that the complementarity between technological versus human approach is a crucial issue of the energy transition. More research is expected on this aspect to ensure that more sustainable behaviours really occur. 


\section{References}

Abrahamse, W., 2007. Energy conservation through behavioral change: Examining the effectiveness of a tailor-made approach, University Library of Groningen.

Abrahamse, W. \& Matthies, E., 2018. Informational strategies to promote pro-environmental behaviour: changing knowledge, awareness and attitudes. Environmental psychology: An introduction, 223-232.

Abrahamse, W. \& Steg, L., 2009. How do socio-demographic and psychological factors relate to households' direct and indirect energy use and savings? Journal of economic psychology 30(5), 711-720.

Abrahamse, W., Steg, L., Vlek, C. \& Rothengatter, T., 2005. A review of intervention studies aimed at household energy conservation. Journal of environmental psychology, 25(3), 273291.

Barr, S., Gilg, A. W. \& Ford, N., 2005. The household energy gap: examining the divide between habitual-and purchase-related conservation behaviours. Energy policy 33(11), 14251444.

Betis, G., Cassandras, C. G. \& Nucci, C. A., 2018. Smart Cities [Scanning the Issue]. Proceedings of the IEEE 106(4), 513-517.

Black, J. S., Stern, P. C. \& Elworth, J. T., 1985. Personal and contextual infl uences on household energy adaptations. Journal of Applied Psychology 70, 3-21.

Botetzagias, I., Malesios, C. \& Poulou, D., 2014. Electricity curtailment behaviors in Greek households: Different behaviors, different predictors. Energy Policy 69, 415-424.

Bryson, A., Dorsett, R. \& Purdon, S., 2002. The use of propensity score matching in the evaluation of labour market policies. Working Paper No. 4, Department for Work and Pensions.

Büchs, M., Hinton, E. \& Smith, G., 2015. 'It helped me sort of face the end of the world': The role of emotions for third sector climate change engagement initiatives. Environmental Values 24(5), 621-640.

Bull, R., Lemon, M., Everitt, D. \& Stuart G., 2015. Moving beyond feedback: Energy behaviour and local engagement in the United Kingdom. Energy Research \& Social Science 8, 32-40.

Caliendo, M. \& Kopeinig, S., 2008. Some practical guidance for the implementation of propensity score matching. J. of economic surveys 22(1), 31-72.

Caragliu, A. \& Del Bo, C. F., 2018. Smart innovative cities: The impact of Smart City policies on urban innovation. Technological Forecasting and Social Change.

https://doi.org/10.1016/j.techfore.2018.07.022 
Carlsson-Kanyama, A. \& Lindén, A.L., 2007. Energy efficiency in residences-challenges for women and men in the North. Energy Policy 35 (4), 2163-2172.

Chen, J., Wang, X. \& Steemers, K., 2013. A statistical analysis of a residential energy consumption survey study in Hangzhou, China. Energy and Buildings 66, 193-202.

Darby, S., 2010. Smart metering: what potential for householder engagement?. Building Research \& Information 38 (5), 442-457.

de Jong, M., Joss, S., Schraven, D., Zhan, C. \& Weijnen, M., 2015. Sustainable-SmartResilient-Low Carbon-Eco-Knowledge Cities; Making sense of a multitude of concepts promoting sustainable urbanization. J. Clean. Prod. 109, 25-38.

Ehrhardt-Martinez, K., Donnelly, K. A. \& Laitner, S., 2010. Advanced metering initiatives and residential feedback programs: a meta-review for household electricity saving opportunities. American Council for an Energy-Efficient Economy, Washington.

Ek, K. \& Söderholm, P., 2010. The devil is in the details: Household electricity saving behavior and the role of information. Energy Policy 38(3), 1578-1587.

Gadenne, D., Sharma, B., Kerr, D. \& Smith, T., 2011. The influence of consumers' environmental beliefs and attitudes on energy saving behaviours. Energy policy 39(12), 76847694.

Gardner, G. T. \& Stern, P. C., 2002. Environmental Problems and Human Behavior. Second Edition. Boston: Pearson.

Geller, E. S., 2002. The challenge of increasing proenvironment behavior. Handbook of environmental psychology 2, 525-540.

Gifford, R., 2011. The dragons of inaction: Psychological barriers that limit climate change mitigation and adaptation. American psychologist 66(4), 290.

Gram-Hanssen, K., Kofod, C., \& Petersen, K. N., 2004. Different everyday lives, different patterns of electricity use, in ACEEE Summer Study on Energy Efficiency in Buildings.Hargreaves \& al.

Hargreaves, T., Nye, M., \& Burgess, J., 2010. Making energy visible: A qualitative field study of how householders interact with feedback from smart energy monitors. Energy policy 38(10), 6111-6119.

Hartman, R. S., 1988. Self-selection bias in the evolution of voluntary energy conservation programs. The Review of Economics and Statistics, 448-458.

Heckman, J., Ichimura, H., Smith, J. \& Todd, P., 1998. Characterizing selection bias using experimental data. Econometrica 66(5), 1017-1098.

Huebner, G., Shipworth, D., Hamilton, I., Chalabi, Z. \& Oreszczyn, T., 2016. Understanding electricity consumption: A comparative contribution of building factors, socio-demographics, appliances, behaviours and attitudes. Applied energy 177, 692-702. 
Innocent, M. \& Francois-Lecompte, A., 2018. The values of electricity saving for consumers. Energy policy 123, 136-146.

Jensen, T., Holtz, G. \& Chappin, É. J., 2015. Agent-based assessment framework for behavior-changing feedback devices: Spreading of devices and heating behavior. Technological Forecasting and Social Change 98, 105-119.

Jones, R. V., Fuertes, A. \& Lomas, K. J., 2015. The socio-economic, dwelling and appliance related factors affecting electricity consumption in domestic buildings. Renewable and Sustainable Energy Reviews 43, 901-917.

Karvonen, A., 2013. Towards systemic domestic retrofit: a social practices approach. Build. Res. Inf. 41, 563-574.

Kendel, A., Lazaric, N. \& Maréchal, K., 2017. What do people 'learn by looking' at direct feedback on their energy consumption? Results of a field study in Southern France. Energy Policy 108, 593-605.

Lallouet, L., 2018. Évaluation socio-économique au périmètre de la collectivité et recommandations pour la mise en œuvre d'une animation territoriale de la MDE, Internal report of the SOLENN experiment, 26 pages.

Lechner, M., 2002. Program heterogeneity and propensity score matching: An application to the evaluation of active labor market policies. Review of Economics and Statistics 84(2), 205220.

Lindenberg, S. \& Steg, L., 2007. Normative, gain and hedonic goal frames guiding environmental behavior. Journal of Social Issues 63(1), 117-137.

Marikyan, D., Papagiannidis, S. \& Alamanos, E., 2019. A systematic review of the smart home literature: A user perspective. Technological Forecasting and Social Change 138, 139154.

Martin, C. J., Evans, J. \& Karvonen, A., 2018. Smart and sustainable? Five tensions in the visions and practices of the smart-sustainable city in Europe and North America. Technological Forecasting and Social Change 133, 269-278.

Mills, B. \& Schleich, J., 2012. Residential energy-efficient technology adoption, energy conservation, knowledge, and attitudes: An analysis of European countries. Energy Policy 49, 616-628.

McMeekin, A. \& Southerton, D., 2012. Sustainability transitions and final consumption: practices and socio-technical systems. Technol. Anal. Strateg. Manag. 24, 345-361.

Ohler, A. M. \& Billger, S. M., 2014. Does environmental concern change the tragedy of the commons? Factors affecting energy saving behaviors and electricity usage. Ecological Economics 107, 1-12. 
Petrillo, J., Cano, S. J., McLeod, L. D. \& Coon, C. D., 2015. Using classical test theory, item response theory, and Rasch measurement theory to evaluate patient-reported outcome measures: a comparison of worked examples. Value in Health 18(1), 25-34.

Poortinga, W., Steg, L., Vlek, C. \& Wiersma, G., 2003. Household preferences for energysaving measures: A conjoint analysis. Journal of Economic Psychology 24(1), 49-64.

RTE 2015. Bilan électrique 2015.

http://www.rte-france.com/sites/default/files/2015_bilan_electrique.pdf (accessed 15.02.2018)

Sardianou, E., 2007. Estimating energy conservation patterns of Greek households. Energy Policy 35(7), 3778-3791.

Sorrell, S., Dimitropoulos, J. \& Sommerville, M., 2009. Empirical estimates of the direct rebound effect: A review. Energy Policy 37, 1356-1371.

Steg, L. \& Vlek, C., 2009. Encouraging pro-environmental behaviour: An integrative review and research agenda. Journal of environmental psychology 29(3), 309-317.

Stern, P. C., 2000. Toward a coherent theory of environmentally significant behavior. Journal of Social Issues 56(3), 407-424.

Stromback, J., Dromacque, C. \& Yassin, M. H., 2011. The potential of smart meter enabled programs to increase energy and systems efficiency: a mass pilot comparison Short name: Empower Demand. Vaasa ETT.

Svenfelt, Å., Engström, R. \& Svane, Ö., 2011. Decreasing energy use in buildings by $50 \%$ by 2050 - A backcasting study using stakeholder groups. Technological Forecasting and Social Change 78(5), 785-796.

Sweeney, J. C., Kresling, J., Webb, D., Soutar, G. N. \& Mazzarol, T., 2013. Energy saving behaviours: Development of a practice-based model. Energy Policy 61, 371-381.

Sweeney, J. C., Webb, D., Mazzarol, T. \& Soutar, G. N., 2014. Self-determination theory and word of mouth about energy-saving behaviors: an online experiment. Psychology \& Marketing 31(9), 698-716.

Thøgersen, J. \& Grønhøj, A., 2010. Electricity saving in households - A social cognitive approach. Energy Policy 38(12), 7732-7743.

Urban, J. \& Ščasný, M., 2016. Structure of Domestic Energy Saving: How Many Dimensions? Environment and Behavior 48(3), 454-481.

Viitanen, J. \& Kingston, R., 2014. Smart cities and green growth: outsourcing democratic and environmental resilience to the global technology sector. Environ. Plan. A 46, 803-819.

Wilson, C. \& Dowlatabadi, H., 2007. Models of decision making and residential energy use. Annual review of environment and resources, 32. 


\section{Annex 1}

Descriptive statistics of the 16 tested covariates

\begin{tabular}{|c|c|c|c|c|c|c|c|c|}
\hline \multicolumn{4}{|c|}{$\begin{array}{l}\text { The nine selected covariates and modalities involved are } \\
\text { in grey. }\end{array}$} & $\begin{array}{l}\text { Total } \\
\text { Sample }\end{array}$ & $\begin{array}{l}\text { Control } \\
\text { Group }\end{array}$ & $\begin{array}{c}\text { CC } \\
\text { Group }\end{array}$ & $\begin{array}{l}\text { HAS } \\
\text { Group }\end{array}$ & $\begin{array}{c}\text { IC } \\
\text { Group }\end{array}$ \\
\hline \multicolumn{2}{|c|}{ Indicators } & \multicolumn{2}{|c|}{ Modalities } & $\mathrm{n}=162$ & $\mathrm{n}=89$ & $\mathrm{n}=27$ & $\mathrm{n}=18$ & $\mathrm{n}=28$ \\
\hline \multirow{2}{*}{\multicolumn{2}{|c|}{$\overline{S e x}$}} & \multicolumn{2}{|l|}{ Female } & $47 \%$ & $49 \%$ & $48 \%$ & $39 \%$ & $43 \%$ \\
\hline & & \multicolumn{2}{|l|}{ Male } & $53 \%$ & $51 \%$ & $52 \%$ & $61 \%$ & $57 \%$ \\
\hline \multirow{5}{*}{\multicolumn{2}{|c|}{$\begin{array}{l}\text { Age } \\
\text { (at start of the } \\
\text { experiment) }\end{array}$}} & \multicolumn{2}{|l|}{$25-39$} & $9 \%$ & $7 \%$ & $15 \%$ & $17 \%$ & $4 \%$ \\
\hline & & \multicolumn{2}{|l|}{$40-54$} & $20 \%$ & $21 \%$ & $19 \%$ & $17 \%$ & $18 \%$ \\
\hline & & \multicolumn{2}{|l|}{$55-64$} & $29 \%$ & $24 \%$ & $33 \%$ & $39 \%$ & $36 \%$ \\
\hline & & \multicolumn{2}{|l|}{65 and over } & $38 \%$ & $44 \%$ & $30 \%$ & $22 \%$ & $39 \%$ \\
\hline & & \multicolumn{2}{|l|}{ undisclosed } & $4 \%$ & $4 \%$ & $4 \%$ & $6 \%$ & $4 \%$ \\
\hline \multirow{3}{*}{\multicolumn{2}{|c|}{ House size }} & \multicolumn{2}{|l|}{1 person } & $22 \%$ & $27 \%$ & $26 \%$ & $6 \%$ & $14 \%$ \\
\hline & & \multicolumn{2}{|l|}{2 persons } & $49 \%$ & $48 \%$ & $44 \%$ & $39 \%$ & $61 \%$ \\
\hline & & \multicolumn{2}{|c|}{3 persons or more } & $29 \%$ & $25 \%$ & $30 \%$ & $56 \%$ & $25 \%$ \\
\hline \multicolumn{2}{|l|}{ Owner/tenant } & \multicolumn{2}{|c|}{ Owner } & $81 \%$ & $76 \%$ & $81 \%$ & $94 \%$ & $86 \%$ \\
\hline \multirow{7}{*}{\multicolumn{2}{|c|}{$\begin{array}{l}\text { Socio-professional } \\
\text { category }\end{array}$}} & \multicolumn{2}{|c|}{ Craftsman, shopkeeper... } & $5 \%$ & $4 \%$ & $4 \%$ & $6 \%$ & $7 \%$ \\
\hline & & \multicolumn{2}{|c|}{ Farmer } & $1 \%$ & $1 \%$ & $0 \%$ & $0 \%$ & $0 \%$ \\
\hline & & \multicolumn{2}{|c|}{ Qualified working population } & $30 \%$ & $30 \%$ & $26 \%$ & $39 \%$ & $29 \%$ \\
\hline & & \multicolumn{2}{|c|}{ Technicians and inter. Prof. } & $27 \%$ & $25 \%$ & $33 \%$ & $17 \%$ & $32 \%$ \\
\hline & & Employees & & $27 \%$ & $27 \%$ & $26 \%$ & $33 \%$ & $25 \%$ \\
\hline & & Blue-collar & orkers & $7 \%$ & $10 \%$ & $7 \%$ & $6 \%$ & $0 \%$ \\
\hline & & No formal $\mathrm{p}$ & ofession & $3 \%$ & $2 \%$ & $4 \%$ & $0 \%$ & $7 \%$ \\
\hline Education lev & & Graduate ed & cation & $48 \%$ & $45 \%$ & $48 \%$ & $67 \%$ & $43 \%$ \\
\hline & & Bachelor's c & gree & $21 \%$ & $22 \%$ & $22 \%$ & $11 \%$ & $21 \%$ \\
\hline & & Vocational & ualification & $21 \%$ & $22 \%$ & $22 \%$ & $11 \%$ & $21 \%$ \\
\hline & & Without des & ees & $10 \%$ & $10 \%$ & $7 \%$ & $11 \%$ & $14 \%$ \\
\hline Type of Hous & & Collective & & $26 \%$ & $27 \%$ & $26 \%$ & $17 \%$ & $29 \%$ \\
\hline & & Individual & & $73 \%$ & $72 \%$ & $74 \%$ & $83 \%$ & $71 \%$ \\
\hline & & Other & & $1 \%$ & $1 \%$ & $0 \%$ & $0 \%$ & $0 \%$ \\
\hline Electric heati & & & & $30 \%$ & $28 \%$ & $22 \%$ & $28 \%$ & $43 \%$ \\
\hline Electric wate & heat & & & $49 \%$ & $47 \%$ & $48 \%$ & $61 \%$ & $50 \%$ \\
\hline Construction & Bef & 1949 & & $4 \%$ & $8 \%$ & $0 \%$ & $0 \%$ & $0 \%$ \\
\hline date & Bet & n 1949 and & 974 & $30 \%$ & $30 \%$ & $33 \%$ & $33 \%$ & $25 \%$ \\
\hline & betv & n 1975 and 2 & & $50 \%$ & $48 \%$ & $52 \%$ & $33 \%$ & $64 \%$ \\
\hline & $\mathrm{Nev}$ & dwelling (bu & It after 2004) & $12 \%$ & $10 \%$ & $11 \%$ & $28 \%$ & $7 \%$ \\
\hline & Not & own & & 4 & 3 & 4 & 6 & 4 \\
\hline Initial percep & & & Strong & $54 \%$ & $61 \%$ & $63 \%$ & $33 \%$ & $36 \%$ \\
\hline $\begin{array}{l}\text { effectiveness } \\
\text { (1 item) }\end{array}$ & dail & estures & Low & $46 \%$ & $39 \%$ & $37 \%$ & $67 \%$ & $64 \%$ \\
\hline Initial Intend & $\overline{l p u}$ & se to save & Strong & $26 \%$ & $30 \%$ & $37 \%$ & $11 \%$ & $11 \%$ \\
\hline electricity(1 i & & & Low & $74 \%$ & $70 \%$ & $63 \%$ & $89 \%$ & $89 \%$ \\
\hline Initial Energy & $\overline{\text { cultu }}$ & scoring $(6$ & Strong & $22 \%$ & $18 \%$ & $30 \%$ & $33 \%$ & $21 \%$ \\
\hline items $)^{a}$ & & & Low & $78 \%$ & $82 \%$ & $70 \%$ & $67 \%$ & $79 \%$ \\
\hline Age & & & & $59.5(12.4)$ & $60.3(12.5)$ & $57.8(11.4)$ & $54.0(13.0)$ & $62.2(12.4)$ \\
\hline Surface area & & & & $108(37)$ & $104(33)$ & $111(39)$ & $108(31)$ & $116(50)$ \\
\hline Number of ele & tric & liances & & $17.3(4.3)$ & $16.7(4.3)$ & $17.3(3.3)$ & $19.5(4.5)$ & $17.8(4.7)$ \\
\hline
\end{tabular}

Modes of category indicator values are given in bold. Other numerical indicators: mean (standard deviation).

${ }^{a}$ score based on six items for measuring knowledge of energy culture with correct and incorrect answers. Answers were recorded in terms of 1-0 (true-false) modalities. 
Annex 2

Means and standard deviations of variables used to build the outcome variables

\begin{tabular}{|c|c|c|c|c|c|c|c|c|c|}
\hline & \multirow[b]{3}{*}{$\mathrm{N}$} & \multicolumn{4}{|c|}{$\begin{array}{l}\text { Electricity Index } \\
\text { (EI) }\end{array}$} & \multicolumn{4}{|c|}{$\begin{array}{l}\text { Electricity Saving Practice Intensity } \\
\text { (EPI) }\end{array}$} \\
\hline & & \multicolumn{2}{|c|}{ EI $P_{1}(k W h)$} & \multicolumn{2}{|c|}{ EI $P_{2}(k W h)$} & \multicolumn{2}{|c|}{$\mathrm{EPI} \mathrm{T}_{1}$} & \multicolumn{2}{|c|}{$\mathrm{EPI} \mathrm{T}_{2}$} \\
\hline & & Mean & St. Dev. & Mean & St. Dev. & Mean & St. Dev. & Mean & St. Dev. \\
\hline Total & 162 & 2841 & 2306 & 2697 & 2212 & 3.68 & 0.47 & 3.69 & 0.50 \\
\hline Control Group (CG) & 89 & 2643 & 2361 & 2527 & 2217 & 3.66 & 0.48 & 3.63 & 0.53 \\
\hline Collective coaching (CC) & 27 & 2531 & 1760 & 2419 & 1783 & 3.82 & 0.43 & 3.81 & 0.45 \\
\hline Home Automation system (HAS) & 18 & 3591 & 2508 & 3333 & 2398 & 3.54 & 0.54 & 3.57 & 0.48 \\
\hline Individual Coaching (IC) & 28 & 3289 & 2289 & 3100 & 2307 & 3.67 & 0.40 & 3.87 & 0.38 \\
\hline Human Support (CC+IC) & 55 & 2917 & 2081 & 2766 & 2095 & 3.74 & 0.42 & 3.84 & 0.42 \\
\hline Technological support (HAS+IC) & 46 & 3407 & 2382 & 3191 & 2346 & 3.62 & 0.47 & 3.76 & 0.45 \\
\hline
\end{tabular}

